\title{
MARKETING THE MACHINE: THE CONSTRUCTION OF ELECTROTHERAPEUTICS AS VIABLE MEDICINE IN EARLY VICTORIAN ENGLAND
}

\author{
by
}

\section{IWAN RHYS MORUS *}

In 1863, Desmond Fitz-gerald, the editor of The Electrician, a popular electrical magazine, responded to his readers' frequent requests for more information about the medical uses of electricity with an editorial on the subject. He claimed that electrotherapy was by then a well-attested form of medical treatment and singled out Dr Golding Bird as one of those "eminent Physicians" who had been responsible for establishing electricity as a viable therapy during the $1830 \mathrm{~s}$ and $1840 \mathrm{~s} .{ }^{1} \mathrm{He}$ was referring to the work carried out by Bird at Guy's Hospital in London during the 1830s and 1840s.

Similarly, a correspondent in the Lancet, writing in 1859 and quoting with approval a recent report from the French military authorities, draw attention to electrotherapeutics' new respectability. He cited two main reasons: the improved electrical technology which made the treatment easy to apply and the progress of knowledge of the nature and functions of the nervous system. ${ }^{2}$ Colwell in his idiosyncratic history of electrotherapeutics also cited Golding Bird's work at Guy's as a key moment in the emergence of electrotherapeutics. ${ }^{3}$

In these three texts, the early Victorian period is presented as the time when electrotherapeutics in England was transformed into viable medicine. Previous practice is represented as empiric-ridden and unsystematic. Such a representation was also a key feature in the writings of those during the period who presented themselves as engaged in a new and different kind of electrotherapeutics. The aim of this paper is to deconstruct this history and to uncover the strategies adopted by men such as

\footnotetext{
* Iwan Rhys Morus, Ph.D., University of Cambridge, Department of History and Philosophy of Science, Free School Lane, Cambridge CB2 3RH.

My research on medical electricity has been carried out during the course of a fellowship financed by the Wellcome Trustees. I wish to record my gratitude for their generosity. I would also like to thank Simon Schaffer and Sonia Uyterhoeven for useful discussions, and two anonymous referees for their helpful criticisms of an earlier version of this paper.

1 [Desmond Fitz-Gerald], 'Medical electricity', The Electrician, 1863, vol. 3, p. 239.

2 SCRUTATOR, in the Lancet, 1859, i: 280.

${ }^{3}$ Hector A. Colwell, An essay on the history of electrotherapy and diagnosis, London, Heinemann, 1922, pp. 84-5.
} 


\section{Marketing the machine}

Golding Bird to transform electrotherapeutics, or to convince others that electrotherapeutics had in fact undergone a transformation. Bird's work in particular changed the social context within which electricity was applied to the body and also transformed the intellectual context within which the issue of electricity's relationship to the body was discussed.

The British medical profession during the $1830 \mathrm{~s}$ was in a state of some flux. The vast social changes associated with the Industrial Revolution had greatly increased the number of practitioners and the demand for their services. ${ }^{4}$ The profession remained dominated however by the "three estates", represented respectively by the Royal College of Physicians, the Royal College of Surgeons, and the Society of Apothecaries. These corporations still governed medicine with an iron hand, protecting their members' privileges whilst denying them to the rapidly expanding group of general practitioners. $^{5}$

A gap was developing between surgeons and physicans employed by the large London hospitals and the broad mass of practitioners. Appointments at the hospitals were limited. Whilst they provided their incumbents with little in the way of direct financial reward, they allowed them to develop the experience and reputation needed to acquire a large and lucrative private practice. Hospital medical schools also provided a substantial income for hospital incumbents since students were required to pay the lecturers for the privilege of attendance. ${ }^{6}$ Hospital appointments usually required the patronage of senior Fellows of the Royal Colleges.

The majority of practitioners felt that the old corporations did not adequately represent their interests. The first half of the century saw the foundation of a number of medical societies ranging in political outlook from radical to moderate, but all calling for medical reform. In 1823 Thomas Wakley founded the Lancet, which for the next several decades was to be a radical thorn in the flesh of the medical establishment. In 1828 the dissenting London University opened its doors, offering to medical students an alternative to the expensive hospital medical schools and challenging orthodox methods of teaching. ${ }^{7}$

New practices could flourish in such an atmosphere. Mesmerism, for example, revived briefly at the London University during the late $1830 \mathrm{~s}^{8}$ Innovation could also be seen as dangerous, however, as the case of mesmerism illustrates. Like mesmerism, electrotherapeutics could easily be tarred with the brush of heterodox and subversive

\footnotetext{
${ }^{4}$ Ivan Waddington, The medical profession in the Industrial Revolution, Dublin, Gill \& Macmillan, 1984.

${ }^{5}$ For an outline of the chaotic state of the medical professions in the early nineteenth century see $\mathbf{M}$. Jeanne Peterson, The medical profession in mid-Victorian London, Berkeley and Los Angeles, University of California Press, 1978, esp. chapter 1.

${ }^{6}$ See Ivan Waddington, 'General practitioners and consultants in early nineteenth century England: the sociology of an intra-professional conflict', in John Woodward and David Richards (eds), Health care and popular medicine in nineteenth century England: essays in the social history of medicine, London, Croom Helm, 1977, pp. 164-88.

${ }^{7}$ See Adrian Desmond, 'Lamarckism and democracy: corporations, corruption and comparative anatomy in the 1830s', in James R. Moore (ed.), History, humanity and evolution: essays for John C. Greene, Cambridge University Press, 1989, pp. 99-130; and idem, The politics of evolution, University of Chicago Press, 1989.

${ }^{8}$ Alison Winter, 'Ethereal epidemic: mesmerism and the introduction of inhalation anaesthesia to early Victorian London', Soc. Hist. Med., 1991, 4: 1-27.
} 


\section{Iwan Rhys Morus}

materialism. It could also be dismissed as mere quackery. New practices had to be provided with genealogies and social settings that insulated them from such attacks.

It was against such a background that Golding Bird pursued his career. A variety of intellectual and social resources were available to budding medical practitioners during this period. Success would be contingent upon convincing others, particularly the medical élite, of the validity and social acceptability of one's practices. This paper examines the rhetorical and practical strategies adopted by Bird and others to pursue electrotherapeutics and to differentiate their work from both past assumptions and contemporary competition.

\section{ELECTROTHERAPEUTICS AT GUY'S HOSPITAL}

Golding Bird became a pupil at Guy's Hospital in 1832, having been apprenticed to the London apothecary William Pretty since the end of 1829. During the course of his studies there, he succeeded in attracting the patronage of both Astley Cooper, then the senior Surgeon at the hospital, and Thomas Addison, then Assistant Physician. He was licensed by the Society of Apothecaries in 1836. In 1838 he took the degree of MD at St. Andrews and became a licentiate of the Royal College of Physicians in 1840, becoming a Fellow four years later.

Bird was appointed to lecture on natural philosophy at the Guy's Medical School in 1836. He was an enthusiastic chemist and had already produced a number of papers, particularly on the chemical analysis of blood and urine. ${ }^{9}$. He joined the London Electrical Society shortly after its foundation in 1837. Bird was Physician to the Finsbury Dispensary from 1838 to 1843 and also lectured at the Aldersgate Medical School. ${ }^{10}$

In October 1836 an "electrifying room" was fitted up at the hospital at the instruction of Benjamin Harrison, the Treasurer of Guy's. Bird was placed in charge of the establishment. It is now impossible to recover the details of the decision to establish this addition to the hospital's resources. The surviving minute books of the hospital's various committees are very patchy in their coverage of the early nineteenth century. The only direct reference to the electrifying room is in a report by the Treasurer to the Court of Committees in August 1838, almost two years after the facility had been set up:

The Treasurer informed the Court that in consequence of the number of patients in the Hospital to whom Electricity was applied, he had found it expedient to appropriate a room for the purpose where the apparatus could be kept in constant order and readiness \& a person who has other occupation in the Hospital is in regular attendance; a senior physicians [sic] pupil regulates the application and keeps a record of all cases where electricity is applied. ${ }^{11}$

\footnotetext{
${ }^{9}$ For an account of Bird's chemical work see N. G. Coley, 'The collateral sciences in the work of Golding Bird (1814-1854)', Med. Hist., 1969, 13: 363-76.

${ }^{10}$ For biographical details of Golding Bird and a list of his publications see William Hale-White,'Golding Bird, assistant physician to Guy's Hospital 1843-1854', Guy's Hosp. Reps, 1926, 76: 1-20.

${ }^{11}$ Minutes of Courts of Committees Guy's Hospital. H9/GY/A3/6/1. 29 August 1838, p. 236. Held at the Greater London Record Office.
} 
Harrison's support was presumably vital in setting up the electrifying room. During his long tenure as Treasurer at the hospital, Harrison had virtually run Guy's as his own private fief. No appointments could be made without his patronage and no new initiative could be carried through without his support. ${ }^{12}$ It is indicative that Harrison felt no need to inform the hospital's governing body of the electrifying room's existence until two years after its establishment.

The electrifying room was in more senses than one an experimental project. This was certainly not the first time electricity had been used in a hospital. John Birch had used electricity at St. Thomas's Hospital before the close of the eighteenth century. ${ }^{13}$ Its use was discontinued after his death in 1815 however, suggesting that it had been at Birch's own initiative and had not been integrated into the hospital routine. Birch himself claimed that he had found it difficult to persuade others to take up electricity themselves. ${ }^{14}$

At Guy's, on the other hand, out-patients and inmates of the hospital attended daily at three o'clock to be submitted to various forms of electrical treatment. A student acted as a Clinical Clerk, making notes on all the cases and registering their progress, the aim being to ascertain the precise therapeutic power of electricity and the range of diseases for which it was applicable. ${ }^{15}$ This was an attempt to regulate the medical application of electricity, circumscribing its use and bringing it inside orthodox practice.

The various forms of treatment utilized a wide range of electrical apparatus taken from the repertoire of techniques and instruments developed by the popular electricians' culture of which Bird himself, as a member of the London Electrical Society, was a part. ${ }^{16}$ Broadly speaking, two types of electricity were employed: ordinary static electricity, derived from a frictional electrical machine or a Leyden Jar, and galvanic electricity, from a battery or some form of electromagnetic apparatus.

Ordinary static electricity was typically employed in one of three ways. Patients could be seated on an insulated stool and connected to the prime conductor of the electrical machine so that their skin surfaces became electrified. This form of treatment was known as the "electric bath". Another closely related and very common form of treatment was to give a patient the electric bath and then draw sparks from the body. Finally, patients could be placed in the circuit of a Leyden Jar so that they underwent a momentary electric shock. More often, however, galvanic

\footnotetext{
12 H. C. Cameron, Mr. Guy's Hospital 1726-1948, London, Longmans, Green \& Co., 1954, pp. $105-87$. Harrison was Treasurer from 1797 until 1848. His influence was such that he was familiarly known as "King" Harrison. For more details of his role at Guy's see Amalie M. Kass and Edward H. Kass, Perfecting the world: the life and times of Dr. Thomas Hodgkin 1798-1866, Boston, San Diego, and New York, Harcourt Brace Jovanovich, 1988.

${ }^{13}$ E. M. McInnes, St. Thomas' Hospital, London, George Allen \& Unwin, 1963, p. 149.

${ }^{14}$ See his biography in DNB.

${ }^{15}$ See Golding Bird, 'Report on the value of electricity as a remedial agent in the treatment of diseases', Guy's Hosp. Reps, 1841, 6: 81-120, p. 84.

${ }^{16}$ For an account of popular electricity in early Victorian London see Iwan Rhys Morus, 'The politics of power: reform and regulation in the work of William Robert Grove', Ph.D. thesis, University of Cambridge, 1989, chapter 1. Bird's membership of this culture was to be an important resource in his electrotherapeutic endeavours.
} 
electricity was used in electric shock treatment, particularly when a large dose of electricity was deemed desirable. ${ }^{17}$

An important feature of the experiments carried out at Guy's Hospital was that electrotherapeutics was confined to the treatment of specific nervous disorders, most frequently chorea and hysterical paralysis. Bird and his associates were keen to emphasize that, unlike many past practitioners, they did not employ electricity as an universal panacea or a last-ditch resort when other forms of therapy had failed. By circumscribing the therapy's use in this manner, they aimed to present their use of electricity as a rational practice, immune from charges of empiricism. ${ }^{18}$

This point was emphatically made in the first paper which publicly discussed the use of electricity at Guy's. In a contribution to Guy's Hospital Reports, Thomas Addison represented his past practice as a failure to realize the efficacy of electrotherapeutics:

It is, nevertheless, much to be feared, that many persons, like myself, have been led greatly to underrate its efficacy, either in consequence of its vague and indiscriminate recommendation, or from the inefficient and careless manner in which it has been applied. Certain it is, that, although I have often ordered it myself, and have more frequently witnessed its employment by others, I had never for a moment entertained the belief that it possessed the power over the disorders alluded to, which I am now inclined to concede it. ${ }^{19}$

Addison's implication was that whilst previous uses of electricity had been empirical and indiscriminate, the work done in the electrifying room was a regulated, rational application of the therapy.

In his first contribution on electrotherapeutics to Guy's Hospital Reports, Bird amassed an impressive list of case histories to support his claim. In the section dealing with the electrical treatment of chorea he listed thirty-six cases that had been treated since the electrifying room's establishment. In only one of them had the treatment had no beneficial effect. He also provided a table of patients treated for amenorrhoea, listing twenty-four cases, of which only the first four were unsuccessful. ${ }^{20}$

The role of the patient in this context was unambiguously that of the experimental object. Patients at the London hospitals were invariably drawn from the poorer sections of the working classes. Their perception of the hospital was as a place of death where at best their bodies would be manipulated for the amusement of others,

${ }^{17}$ Bird, op. cit., note 15 above, pp. 85-7.

18 "Empiricism" as used by early nineteenth-century medical practitioners invariably had derogatory connotations. An empirical therapy was one which was not based on a rational understanding of the method whereby the therapy affected the human body. "Rational" therapy did not necessarily imply a theoretical commitment to any particular account of the human body, it might for example be based on a systematic reading of past case histories and the treatments employed there. This would initially be the case with the marketing of electrotherapeutics.

19 Thomas Addison, 'On the influence of electricity, as a remedy in certain convulsive and spasmodic diseases', Guy's Hosp. Reps, 1837, 2: 493-507, pp. 493-4. The choice of the prestigious Addison as opposed to the largely unknown Bird to make the first announcement of the electrifying room's activities was clearly strategic. In his introduction Addison made his indebtedness to Bird quite clear.

${ }^{20}$ Bird, op. cit., note 15 above, pp. 88-89, 116. 


\section{Marketing the machine}

and at worst they would end up on the dissecting table. ${ }^{21}$ Their position as objects of charity at the hospital meant that they were no longer permitted to adjudicate over the treatment of their own bodies. Indeed one of the advantages of a hospital appointment was that it provided a steady supply of subjects upon which the doctor could improve his techniques and develop new forms of treatment. ${ }^{22}$

The practitioners of electrotherapeutics were no exception. An interesting insight into the attitude of men like Bird towards their patients may be gained from the following letter:

Dr. Cholmely wishes to assure Mr. Bird that he never entertained the thought of making any complaint of Galvanic neglect. He is sorry to learn that Mr. Bird is ill, + he upon no account wishes the Clinical female to undergo the Voltaic process for the cure of aphasia until the reestablishment of his health. ${ }^{23}$

Patients were regarded as objects who would "undergo the ... process" rather than as people to be treated.

By far the most common symptoms exhibited by patients presented at the electrifying room were paralysis and the involuntary movement of limbs. Such symptoms were often accompanied in female patients by irregular menstruation. The onset of these symptoms was frequently attributed to particular traumatic events in the patient's past. Sarah Wheeler, for example, admitted on 5 November 1839 suffering from involuntary motion of the right arm and shoulder, attributed her condition to "fear, produced by the threats of her schoolmistress". 24

Electricity was rarely the therapy of first resort, or the only therapy in a regime of treatment. Typically, the patient would initially be treated by a regimen of chemicals, sulphate of zinc being the most common antispasmodic drug administered. Electricity in the form of sparks drawn from the spine or passed through the affected limb would be used only if the drugs failed to bring about an improvement in the patient's condition. Once electricity had been prescribed, patients attended the electrifying room for treatment on a daily basis until their symptoms subsided. Cessation of involuntary movement, and in the case of female patients the resumption of normal menstruation, were taken as signs that the therapy had been successful and the patient would be discharged.

Men such as Golding Bird wanted not only large and successful medical practices, they were intent on making their reputations in the new discipline of physiology. Indeed, a "scientific" reputation was rapidly becoming an useful component in a practitioner's career capital. Bird had already used his chemical expertise at Guy's to attract the attention of Sir Astley Cooper. He had taken advantage of the Pupils'

\footnotetext{
${ }^{21}$ For a fascinating account of the early nineteenth-century patient's perception of the hospital see Ruth Richardson, Death, dissection and the destitute, London, Routledge \& Kegan Paul, 1988.

${ }^{22}$ On the fluid power-relation between patient and practitioner in the eighteenth century see Malcolm Nicolson, 'The metastatic theory of pathogenesis and the professional interests of the eighteenth-century physician', Med. Hist., 1988, 32: 277-300.

23 James Cholmely to Golding Bird, 23 April 1837. Golding Bird Correspondence, Royal College of Surgeons, 129. c. 16. Cholmely was physician at Guy's from 1804 to 1837.

${ }^{24}$ Bird, op. cit., note 15 above, p. 93.
} 
Physical Society's and later the Senior Physical Society's meetings to publicize his chemical endeavours. As a result he was asked to contribute an account of the chemistry of milk to Cooper's The anatomy of the breast. ${ }^{25}$

Another good example is Marshall Hall, who used his physiological expertise to found a highly lucrative private practice despite his lack of hospital affiliation. His work on the pathology of the nervous system moved easily from discussions of electrical vivisections on frogs and rabbits to accounts of experiments carried out on human patients. Hall's language was unambiguous:

I waited with anxiety for opportunities of submitting this question to the decision of experiment ... A little child, aged two years, was perfectly paralytic of the left arm. The slightest shock of galvanism was directed to be applied which should produce an obvious effect. It was uniformly observed that the paralytic limb was agitated by a degree of galvanic energy which produced no effect on the healthy limb. $^{26}$

The use of electricity in such a case was presented as both therapy and experiment. Whilst it cured the patient, it also allowed Hall to generalize from experimental observations made on animals to human subjects.

Golding Bird's close links with other London electricians were a crucial factor in his success. During the 1830s the metropolis sustained a large community of popular electricians interested in electricity as a science of utility and display. This community institutionalized itself in the late 1830s with the foundation of the London Electrical Society, of which Bird was himself an early member. A survey of the Society's activities will indicate the resources they made available which could be exploited by medical electricians. Not only Bird, but others such as Henry Letheby and Alfred Smee had close ties with this electricians' culture. ${ }^{27}$

Two main areas of interest may be constructed out of an examination of the Society's Proceedings. The first interest can be characterized as technological: of approximately 120 papers contributed at meetings and listed in the Proceedings of the London Electrical Society, 45 per cent describe improvements in laboratory apparatus or the development of new techniques and instruments. The first presentation recorded in the Proceedings-Thomas Bradley's exhibition of a thermoelectric battery-is a typical example.

Other contributions which fit well into this category include E. M. Clarke's display of a new electro-magnetic machine; descriptions of new types of voltaic battery by William Leithead and Alfred Smee, and accounts of more convenient apparatus such as Golding Bird's own description of an instrument for breaking contact between the primary wire of an induction coil and an electrometer "without the interposition of manual labour". Bird's new instrument was explicitly designed to render the

\footnotetext{
${ }^{25}$ Coley, op. cit., note 9 above, p. 365. Astley Cooper, On the anatomy of the breast, London, 1840.

${ }^{26}$ Marshall Hall, 'Memoirs on some principles of pathology in the nervous system', Medico-chirurg. Trans., 1839, 22: 191-217, pp. 200-1.

${ }^{27}$ Henry Letheby, 'Nervous and electrical forces', Lond. med. Gaz., 1842, 30: 809-10. This was an abstract of a paper delivered to the London Electrical Society on 16 August 1842. Smee was not a member of the Society but contributed to its proceedings during the early 1840 s.
} 


\section{Marketing the machine}

therapeutic application of electricity more convenient. ${ }^{28}$ E. M. Clarke's new version of the electro-magnetic machine was also avowedly targeted at a medical audience. ${ }^{29}$

The London Electrical Society's other main area of interest may be characterized as cross-disciplinary. Its members were quite happy to describe their science of electricity as the queen of the sciences and to encourage its application in as many spheres as possible. Such an attitude was articulated by H. M. Noad in the closing remarks of his A course of lectures on electricity, galvanism, magnetism, and electro-magnetism:

when we reflect on the prospects, which are held out by the attentive study of electricity, of eventually giving us a closer insight into the operations of nature as connected with the animal, vegetable and mineral kingdoms... little more inducement, will, I imagine, be wanting to increase the number of its cultivators, and to assign it, its proper place, among the most important of the physical sciences. ${ }^{30}$

This was reflected in many of the contributions to the Society's Proceedings. Robert Were Fox for example made numerous contributions on the action of electricity on crystal and rock structures. ${ }^{31}$ Thomas Pine published several papers on the relationship between electricity and vegetable growth. ${ }^{32}$

This interest in the cross-disciplinary applications of electricity certainly extended to an interest in the relationship of electricity to animal and human life. Henry Letheby, for example, contributed numerous descriptions of dissections of the gymnotus electricus and was explicit in his claim that the gymnotus provided direct and conclusive evidence that electricity was the nervous force. Citing Liebig's claim that all vitality was the result of chemical action, he pointed out that electricity was also the result of chemical action. He proceeded to list a number of similar analogies between the nervous force and electricity, concluding that "electricity sent along nerves gives rise to phenomena not to be distinguished from the vital-viz. sensation, motion, and secretion". ${ }^{33}$ This series of analogies he held to be conclusive evidence for the identity of electricity and the nervous force.

That Letheby's was not an isolated enthusiasm is suggested by the arguments in William Leithead's Electricity; its nature, operation, and importance in the phenomena of the universe. Leithead, a chemical consultant who was Secretary to the London Electrical Society, concluded that since such physiological processes as respiration were chemical in nature and that chemical action invariably produced electricity, electricity must be present and have a function in the animal economy. He then went on to consider the relationship of electricity to the nervous force:

\footnotetext{
28 Proc. Lond. Electric Soc., 1841, 1.

${ }^{29}$ Edward M. Clarke. 'Mr. E. M. Clarke's description of his electrical magnetic machine', Philosophical Mag., 3rd ser., 1836, 9: 262-66. His interests were even more explicit in idem, 'A description of a magnetic electrical machine invented by E. M. Clarke', Ann. Electricity, 1836-37, 1: 145-55, where he gave an exhaustive list of the advantages of his machine for "medical gentlemen". See the footnote to p. 149.

${ }^{30}$ Henry M. Noad. A course of eight lectures on electricity, galvanism, magnetism, and electro-magnetism, London, George Knight \& Sons, 1839, pp. 381-2.

${ }^{31}$ For example, Robert W. Fox, 'Influence of electric action on clay', Proc. Lond. Electric Soc., 1841, 1: 43-5.

${ }^{32}$ For example, Thomas Pine, 'The effect of vegetable points on free electricity and the position they hold in the economy of vegetation', ibid., 1843, 2: 149-52.

${ }^{33}$ Letheby, op. cit., note 27 above, p. 810 .
} 


\section{Iwan Rhys Morus}

This leads to a consideration of a subject of the highest importance, that of the nervous principle, as some authors have termed that intermediate something between the body and the soul, by means of which the mind acts upon the material part of our frame, giving rise to the phenomena of thought and perception, and imparting motion to those muscles which are under the control of the will. ${ }^{34}$

Referring to Magendie's researches on the divisions of the anterior and posterior roots of the spinal nerves, he suggested that such an arrangement of the nerves was precisely what was required for electrical circulation:

Such being the fact, it is highly probable that there is an ascending current of the electric fluid, along one portion of the cord, to the brain, affecting the organs of sensation, and a descending current, through the other half, influencing the organs of motion. ${ }^{35}$

In short, the claim that electricity was the nervous force, or at least had a crucial role to play in the animal economy, was a commonplace in the electricians' discourse. ${ }^{36}$ It is not surprising therefore that a young medical practitioner like Golding Bird, moving in such a community, developed an interest in the medical uses of electricity.

This interest was not all that Bird gained from his membership of the electricians' community. As discussed previously, the electricians had an interest in the technology of electricity which extended to its utility. Their emphasis on the technology of display had led to the proliferation of electrical apparatus that could be exploited for a variety of purposes. Bird, therefore, was familiar with the skills and practices needed for the competent manipulation of a wide range of electrical apparatus. He had the competences needed to make electrotherapeutics work as a practical technology. ${ }^{37}$

These practical skills and technologies were however embedded in a culture which was marginal within London's intellectual élite. The electricians' displays of shocks and sparks took place at such venues as the Adelaide Gallery of Practical Science or the Polytechnic Institution rather than in the prestigious surroundings of the Royal Institution or the Royal Society. The administration of electric shocks for therapeutic purposes was a routine part of this popular culture. ${ }^{38}$ The electricians also had links with such irregular practitioners of medical electricity as William Hooper Halse, who

\footnotetext{
34 William Leithead, Electricity; its nature, operation, and importance in the phenomena of the universe, London, 1837. Quoted by William Sturgeon in Ann. Electricity, 1837, 2: 149-52, p. 151.

35 Ibid., p. 152.

${ }^{36}$ The most well-known example is probably the notorious episode of Andrew Crosse's production of insects by electricity. For a detailed account see James Secord, 'Extraordinary experiment: electricity and the creation of life in Victorian England', in David Gooding, Trevor Pinch, and Simon Schaffer (eds), The uses of experiment, Cambridge University Press, 1989, pp. 337-83.

${ }^{37}$ For an account of enculturation and the importance of community membership for the acquisition and transmission of tacit skills and knowledge see Harry M. Collins, Changing order: replication and induction in scientific practice, London, Sage, 1985.

${ }^{38}$ See, for example, William Sturgeon, $A$ course of twelve elementary lectures on galvanism, illustrated with upwards of 100 engravings of experiments and apparatus, London, 1843.
} 


\section{Marketing the machine}

plied his trade from St John's Wood during the $1840 \mathrm{~s} .{ }^{39}$ In order to attract the patronage and support of the medical elite, Bird needed to divorce his practices from this unsavoury context.

The foundation of the electrifying room at Guy's can be read as an attempt to shift physically the social context of electrotherapeutic practice. Rather than being performed in the dubiously popular context of the Adelaide Gallery or the private house of an irregular practitioner, or even within a hospital on an irregular basis and at the whim of individual practitioners, electrotherapeutic treatment could take place within a circumscribed space where its application could be carefully and systematically policed. The hospital apparatus of clinical clerks and assistants could be brought to bear on the practice, rendering it safe for élite medical consumption.

\section{THE RATIONAL FOUNDATION OF ELECTROTHERAPEUTICS}

Electricians commonly regarded electricity's relationship to the nervous fluid as unproblematic: it was, simply, the force that provided the body with vitality. For them, electricity was the guiding force that governed the universe. The electrician Andrew Crosse, for example, suggested that:

It has long been my belief, that the Electric influence is the great principle by which the Almighty puts together, and separates; and that it might be called, metaphorically speaking, the right arm of God. ${ }^{40}$

Such arguments were employed by electricians and irregular practitioners to justify their use of electricity as therapy. They were also deployed to suggest that electrical rather than medical skills were the main requirement for the successful application of electricity to the human body. ${ }^{41}$

The furore which followed Andrew Crosse's claim to have produced insects by electricity was indicative of the high medical and philosophical response to such assertions. Arguments identifying electricity with life were certainly not available to Bird who had been engaged himself in the Crosse controversy, producing experimental evidence contradicting Crosse's claims. ${ }^{42}$ A correspondent in the conservative London Medical Gazette fulminated against the assumption that electricity and the nervous force could be identified. He described the claim as:

another instance of those chimerial fancies of the day, which are perpetually disgracing our profession, and bringing it into contempt with the public; that, like

\footnotetext{
${ }^{39}$ See William Hooper Halse, On the extraordinary remedial efficacy of medical galvanism, when scientifically administered, London, n.d. Halse published on at least one occasion in the electricians' main journal: 'Wonderful effects of voltaic electricity in restoring animal life when the sensorial powers have entirely ceased, or in other words, when death in the common acceptation of the term has actually occurred', Ann. Electricity, 1840, 4: 481-4.

${ }^{40}$ Quoted as an epigraph to C. H. Cleaveland, Galvanism: its application as remedial agent, New York, 1853. I have been unable to find the source of the quotation. For Crosse's activities see Secord, op. cit., note 36 above.

${ }^{41}$ See for example A. H. Christie, Galvanism and its applications as a remedial agent, with occasional hints about doctors and doctrines, abridged from 12th London ed., New York, 1847, pp. 4-6.

${ }^{42}$ Secord, op. cit., note 36 above.
} 
mesmerism, it will meet with a similar fate-to be merely had in memory, and as a tale that were told. ${ }^{43}$

The imputed association of such arguments with mesmerism was doubly dangerous as the mesmerists were even then being widely vilified in the medical press.

Bird had transformed the social context within which electrotherapeutics was practised by bringing the enterprise inside the hospital and inside the electrical room. In that space he had been able to bring the full weight of medical regulatory technology into effect in order to break the link between electrotherapeutics and the popular culture of shocks and sparks with which it had previously been associated. Electrotherapeutics had ceased to be a performance and become a process. New resources would now need to be mobilized to provide a new rationale for the practice. Some of the philosophical apparatus of the gentlemen of science was put to work in order to dissociate electrotherapeutics from any particular ontological claim for the relationship of electricity and the nervous principle. ${ }^{44}$

The ambivalent attitude of orthodox practitioners towards the issue of the relationships of electricity, the nervous fluid, and electrotherapeutics is well illustrated by the discussion under the heading 'Electricitas-Electricity' in the second edition of Jonathan Pereira's magisterial Elements of materia medica and therapeutics (1842). It was an indication of electrotherapeutics' acceptance as orthodox, rational practice that it was included at all in such a text. The first edition of Pereira's work, published in two volumes between 1839 and 1840, had contained no reference to electricity and its uses as a therapeutic agent.

Pereira's discussion of the relationship of electricity and vital phenomena was brief. He noted that "physiologists have long suspected that electricity was the cause of some vital phenomena; and various circumstances lend support to this notion."45 Significantly, the reference cited in support of this assertion was John Abernethy's Enquiry into the probability and rationality of Mr. Hunter's theory of life. ${ }^{46}$ This was an eminently respectable source and no reader remembering the bitter and heated controversy between Abernethy and William Lawrence would be likely to associate Abernethy's name with unorthodoxy. ${ }^{47}$ Pereira made no attempt to link electrotherapeutics explicitly with electrical theories of vital phenomena.

One of the most potent defences of electrotherapeutics was mounted by Golding Bird himself, in a series of lectures before the Royal College of Physicians in March of 1847. ${ }^{48}$ The title of the series specified that Bird would discuss electricity in both its

\footnotetext{
${ }^{43}$ William Bevan, 'An inquiry into the truth of the electrical nature of the nervous principle', Lond. med. Gaz., 1842, 29: 173-6, p. 176.

${ }^{44}$ For a profile of the British scientific élite and its concerns in this period see Jack Morrell and Arnold Thackray, Gentlemen of science: early years of the British Association for the Advancement of Science, Oxford University Press, 1981.

45 Jonathan Pereira, Elements of materia medica and therapeutics, 2nd ed., 2 vols, London, 1842, vol. 1, pp. 34-5.

46 John Abernethy, Enquiry into the probability and rationality of Mr. Hunter's theory of life, London, 1814.

${ }^{47}$ For an account of the controversy between Abernethy and Lawrence see Owsei Temkin, 'Basic science, medicine, and the romantic era', in his The double face of Janus and other essays in the history of medicine, Baltimore, Johns Hopkins University Press, 1977, pp. 345-72.

${ }^{48}$ Golding Bird, 'Lectures on electricity and galvanism, in their physiological and therapeutical relations', Lond. med. Gaz., 1847, 39: 705-11, 799-806, 886-94, 975-82, 1064-72.
} 


\section{Marketing the machine}

physiological and therapeutic relationships. He was thus committed to addressing the contentious issue of electricity's relationship to vital phenomena. His lectures were the first defence of electrotherapeutics to be mounted before that venerable citadel of conservative orthodoxy.

Bird's defence was mounted on two fronts. On the one hand, he linked the practice of electrotherapeutics to the rising new discipline of electrophysiology, particularly as represented in the work of the young Italian natural philosopher Carlo Matteucci, Professor of Physics at the University of Pisa. ${ }^{49}$ On the other hand, he linked his philosophical claims for the relationship of electricity and the vital force to the work of such orthodox and influential theorists of force as Michael Faraday and William Robert Grove.

Bird's lectures before the Royal College of Physicians were liberally sprinkled with references to Matteucci's electrophysiological researches. In particular he drew upon Matteucci's work on the phenomena produced by passing an electric current through the nerves in different directions, to provide a rationale for the therapeutic use of electricity in nervous disorders. In this way electrotherapeutics could be presented as rational without implying a commitment to any particular ontological claim for the nature of the nervous force. It allied itself to a successful and acceptable form of experimental practice rather than to any particular theory of nervous action. ${ }^{50}$

The utilization of various philosophical claims concerning the relationships of the various modes of force was also a form of ontological gerrymandering. The account developed by William Robert Grove avoided the issue of which mode of force had priority over any other, describing the forces as being related by correlation rather than causation. ${ }^{51}$ Michael Faraday's account of the reciprocal relationship between electricity and magnetism could also be put to use in much the same way. ${ }^{52}$

Grove, Professor of Experimental Philosophy at the London Institution from 1841 to 1846 , first developed his account of correlation in a series of lectures delivered there in 1843 . On resigning his post in 1846 he published these lectures, which went through several editions over the next few decades. In both the lectures and the published version Grove defended an account of the physical world and of experimental practices which portrayed the natural philosopher as displaying and manipulating the mutual inter-relationship of the different modes of force.

Grove rejected the notion that experimental natural philosophy was concerned with the discovery of essential causes. His doctrine of correlation was presented as following from a critique of abstract causation.

\footnotetext{
${ }^{49}$ For brief biographical details of Matteucci see G. Moruzzi, 'Matteucci', in Dictionary of scientific biography, New York, Charles Scribner's Sons, 1974, vol. 9, pp. 176-7.

50 Bird, op. cit., note 48 above, pp. 892-3, 1065. For an account of the London electricians' elevation of practice over theory see Iwan Rhys Morus, 'Currents from the underworld: electricity and the technology of display in early Victorian England', Isis, 1992, forthcoming.

51 William R Grove, The correlation of physical forces, 1st ed., London, printed for the Managers of the London Institution, 1846.

52 Michael Faraday, 'Experimental researches in electricity, 14th series', in Experimental researches in electricity, vol. 1, London, 1839, pp. 533-56. The clearest statement of Faraday's views on the relationship of electricity and magnetism is contained in paragraphs $1731-4$.
} 


\section{Iwan Rhys Morus}

The position which I seek to establish in this essay is, that the various imponderable agencies, or the affections of matter which constitute the main objects of experimental physics ... are all Correlative, or have a reciprocal dependence. That neither, taken abstractedly, can be said to be the essential or proximate cause of the others, but that either may, as a force, produce or be convertible into the other, thus heat may mediately or immediately produce electricity, electricity may produce heat; and so of the rest. ${ }^{53}$

The task of the natural philosopher, Grove maintained, was to identify and analyse such relationships between forces on a phenomenal level. The identification of any particular example of correlation was not to be taken as a sign of any deeper ontological unity.

Such an account of the implications of the simply phenomenal relationships between different modes of force was ideal for someone such as Golding Bird, who wished to defend a practice such as electrotherapeutics without committing himself to any particular account of its underlying ontology. Grove's account was itself explicitly concerned to provide a philosophical framework for experimental practices which did not imply any hypothetical account of the nature of either force or matter. ${ }^{54}$

Faraday's claims for the relationship of the electric and magnetic forces were equally useful. Following Oersted's discovery that a magnetized needle "twitched" when placed near a current-carrying wire, several natural philosophers (most notably Ampère and Herschel) had held that electricity was the cause of magnetism. Faraday's discovery of magneto-electricity in 1832 made it equally evident that magnetism could also cause electricity. At the end of his fourteenth series of Experimental researches in electricity, Faraday speculated on the nature of the relationship between electricity and magnetism:

If the lateral or transverse force of electrical currents, or what appears to be the same thing, magnetic power, could be proved to be influential at a distance independently of the intervening contiguous particles, then, as it appears to me, a real distinction, of a high and important kind, would be established between the nature of these two forces. ${ }^{55}$

He suggested that magnetism was a "higher" relation of force than electricity.

In the next series of Experimental Researches, in which Faraday related an account of some experiments on a gymnotus electricus, he explicitly extended this speculation to discuss the relationship of electricity and the nervous force:

Now though I am not as yet convinced by the facts that the nervous fluid is only electricity, still I think that the agent in the nervous system may be an inorganic force; and that if there be reasons for supposing that magnetism is a higher relation of force than electricity, so it may well be imagined that the nervous power may be of a still more exalted character, and yet within the reach of experiment. ${ }^{56}$

${ }^{53}$ Grove, op. cit., note 51 above, pp. 7-8.

${ }^{54}$ See Morus, op. cit., note 16 above, pp. 77-89.

${ }^{55}$ Faraday, op. cit., note 52 above, pp. 550-1.

${ }^{56}$ Michael Faraday, 'Experimental researches in electricity, 15th series', in Experimental researches in electricity, vol. 2, London, 1844, p. 16. 


\section{Marketing the machine}

He proceeded to suggest some experiments which could illuminate the matter.

Golding Bird drew directly on this passage in his account of the relationship of the nervous and electrical forces:

May not one of the uses of the electricity so freely developed in the body, especially that existing in the muscles, be to excite in the nervous chords the vis nervosa, just as currents, if passing near a bar of iron at right angles to its axis, excite magnetism? May not this vis nervosa or nervous polarity excite the contraction of a muscle without actual contact with its fibres ... just as the invisible lines of force emanating from the bars of a magnet act upon the suspended bundles of wire or iron filings? Lastly, may not such nervous force again induce electric currents in any glandular or other organs, just as magnetism in motion will re-excite electricity? thus accounting for what cannot be questioned, the existence of electric currents in certain organs, exclusively excited by, or depending for their existence upon, the integrity of the nervous influence of the part. ${ }^{57}$

In this passage, Bird combined Grove's account of correlation with Faraday's claims for electricity and magnetism, carefully emphasizing that his claim involved analogy of action, not identity.

Bird's success is illustrated by the changes made in the third edition of Jonathan Pereira's Elements of materia medica and therapeutics published in $1849 .{ }^{58}$ The section on the therapeutic uses of electricity was now much expanded, much of the additional material being devoted to a detailed rationale for the application of electricity to the nervous system based on Matteucci's researches in electrophysiology. Pereira differentiated between the action of electricity on the motor, sympathetic, and mixed nerves and described how the effect of the current varied depending upon the direction in which it was applied. ${ }^{59}$ Centrifugal currents directed from the nervous centres to the peripheries produced a certain set of effects whilst centripetal currents directed from the peripheries towards the nervous centres produced a different set of effects.

Similarly, the philosophical concept of correlation was utilized to provide an ontologically neutral framework for electrotherapeutics. In a section entitled 'Correlation of the Electrical and Nervous Forces' Pereira discussed the relationship of electricity and the vis nervosa:

Between electricity and the vis nervosa there exist, both in their development and propagation, several striking analogies, which at one time disposed physiologists to regard these two forces as identical; but the failure of the most competent experimentalists to detect electric currents in the nerves, and the well-ascertained differences in properties between electricity and the vis nervosa, have led more recent physiologists to reject the electrical hypothesis of nervous power, which, in the present state of knowledge, seems to me to be no longer tenable. ${ }^{60}$

\footnotetext{
${ }^{57}$ Bird, op. cit., note 48 above, p. 890 . Roman and italics here reversed for clarity.

58 Jonathan Pereira, Elements of materia medica and therapeutics, 3rd ed., 2 vols, London, 1849.

59 Ibid., vol. 1, pp. 38-40.

60 Ibid., p. 44.
} 


\section{Iwan Rhys Morus}

He then proceeded to differentiate between rational and empirical uses of electricity. Rational uses were those in which it was used to produce one of its known physiological effects. Empirical uses were those where "the indications for its use are not obvious, and in which its methodus medendi, if indeed, it possess any curative power whatever, is unknown."61

The electrotherapeutic practices of men such as Golding Bird were thus successfully dissociated from those of mere quacks and empirics who had no clear rationale for their application of electricity. The success of the new version of electrotherapeutics was presented as being contingent upon a detailed experimental understanding of the action of electricity on the nervous system rather than upon any claim for the precise relationship of electricity and the nervous fluid.

The apparatus of orthodox natural philosophy had successfully insulated the practice of electrotherapeutics from dangerous and potentially subversive connotations. Electrotherapeutics had become "black-boxed" in the sense that it had become a set of routines which could be performed unproblematically without the need for further ontological discussion. ${ }^{62}$ The relevant evidential context was now Matteucci's experiments, which used electricity as an analytic tool, rather than speculation concerning electricity and life. ${ }^{63}$

Bird's lectures were celebrated in the Literary Gazette, which compared his efforts with the recent Elements of electro-biology, published in the same year by Alfred Smee. ${ }^{64}$ In his work Smee attempted to found electrotherapeutics on an account of the human body which explicitly referred all muscular, nervous, and cerebral activity to electrical action. The brain and body were described as a series of voltaic batteries combined in different ways to produce movement, sensation and thought. This was dismissed by the normally moderate Literary Gazette as the fantasy of a misguided madman. Bird's lectures, by comparison, were accorded a very different reception. In the spirit of "true philosophy", the reviewer concluded that "Dr. Bird's lectures afford a fair view of the real progress in electro-biology, and a useful record of experience of electricity as a therapeutic agent." 65 Smee's failure was a salutary warning of the dangers involved in too rash speculation. It should be remembered that Smee was no unknown outsider: he was a member of the Royal College of Surgeons and a Fellow of the Royal Society.

\section{MARKETING THE MACHINE}

In promoting the use of electricity in medicine, men such as Golding Bird had a distinct advantage over the mass of medical practitioners in that they combined their

\footnotetext{
61 Ibid.

62 For black boxes see Bruno Latour, Science in action: how to follow scientists and engineers through society, Milton Keynes, Open University Press, 1987.

${ }^{63}$ The concept of evidential context is spelt out in Trevor Pinch, Confronting nature: the sociology of solar-neutrino detection, Lancaster, Mass., and Dordrecht, Reidel, 1986. For an analysis of the changing evidential contexts for electrical experiments in early Victorian England see Iwan Rhys Morus, 'The sociology of sparks: an episode in the history and meaning of electricity', Soc. Stud. Sci., 1988, 18: 387-417.

${ }^{64}$ Alfred Smee, Elements of electro-biology, or the voltaic mechanism of man; of electro-pathology, especially of the nervous system, and of electrotherapeutics, London, 1849.

${ }^{65}$ Literary Gaz., 1849, p. 845.
} 


\section{Marketing the machine}

medical skills with membership of the electricians' cultural network. Bird's membership of institutions such as the London Electrical Society was a crucial feature of his success since it provided him with the tacit skills and knowledge required to enable him to use complex electrical apparatus successfully. The overlap between the electrical and medical communities was not, however, a large one. The medical contingent did form a significant proportion of the London Electrical Society's membership, but that was small, and they comprised only a tiny percentage of the London medical community as a whole.

If electrotherapeutics was to be marketed successfully to this broader community of medical practitioners it was essential that a new technology be developed that made it easy to apply the treatment without detailed technical knowledge. Early voltaic batteries were expensive and cumbersome, and they required constant attention in order to guarantee their proper functioning. Making electrotherapeutics easy to apply would also deprive electrical quacks of their claims to expertise in the application of electricity.

Bird was certainly aware of the dangers posed to his practice by the activities of quack electricians. In the Lancet in 1846 he fulminated against the activities of self-styled medical galvanists, blaming their success at least partially on the ignorance of his fellow medical practitioners. ${ }^{66}$ He presented his case as being a moral as much as a medical crusade. Shameless charlatans were duping and cheating the public:

These medical galvanists lay heavy contributions on the public, and one of them in the west end of the metropolis, regularly pockets some thousands per year by his practice. There is scarcely a part of London where these irregulars do not exist-the small suburb of Pentonville alone rejoices in two, if not three. ${ }^{67}$

One solution, he suggested, was to educate the medical profession in natural philosophy, for without such education the medical practitioner would be unable to beat the unprincipled quack at his own game.

Bird emphasized that very little training was required to become proficient in electrotherapeutics:

Every practitioner should feel it his duty to be as conversant with the application of electricity and its modifications as of a cupping-glass; and there is no more necessity for increasing the "specialities" of our profession by the electrician or galvanist, than by a qualified administerer of glysters. Largely as I have employed the remedy in question, I have never needed any other electrician than the wife or mother-often the footman or maid-servant. ${ }^{68}$

Such a claim was, to say the least, more than a little disingenuous. Bird himself went on to emphasize that it was only recent improvements in electrical technology, in particular the introduction of the induction coil to replace "the large and cumbrous

\footnotetext{
${ }^{66}$ Golding Bird, 'On the employment of electro-magnetic currents in the treatment of paralysis', Lancet, 1846, i: $649-51$.

${ }^{67}$ Ibid., p. 649.

68 Ibid.
} 
voltaic battery", that rendered electricity easy to apply therapeutically. ${ }^{69}$ The point of his remark was that electrotherapeutics should remain firmly under the control of professionally-trained medical practitioners rather than mere electricians.

Golding Bird had himself been directly involved in attempts to improve the induction coil's ease of use in medical practice. His main innovation was a device which made the repeated switching on and off of the electricity supply, which was essential to the induction coil's action, an automatic process. ${ }^{70}$ His contact-breaker operated by means of a spring and magnet device. When the circuit was complete, a small electromagnet became magnetized, attracting the contact-breaker and thus breaking the circuit. This then demagnetized the electromagnet so that the contactbreaker would be drawn back by the spring to complete the circuit once more.

Bird's efforts were applauded by the surgeon J. Crowch Christophers in the Lancet. Like Bird, Christophers was concerned that electrical quackery could undermine the position of practitioners of electrotherapeutics who wished to remain within the orthodox medical profession. He was fully in favour of Bird's "attempt to wrest a most important agent from the grasp of an unprincipled host of quacks, self-styled 'Medical Galvanists' and 'Medical Electricians' whose ignorance and effrontery eminently tend to bring it into discredit and disuse."71 Like Bird, Christophers emphasized that with the proper equipment, and minimal training, any person could apply the electrical treatment. He thanked him for his efforts in "putting it in the power of all to obtain an efficient apparatus at an outlay so trivial". He concluded that as the result of the efforts of men like Bird:

it is to be hoped, that when the public is made to see that footmen and maidservants, under medical direction, make excellent galvanists and electricians, we may find the self-dubbed "medical galvanist" and "medical electrician" fast returning to more useful, and though, no doubt, less lucrative, more becoming, occupations; for when simplicity and truth begin, mystery and quackery end. ${ }^{72}$

The quacks threatened the orthodox practitioners of electrotherapeutics on two fronts. Not only did their continued existence deny the regulars' claim to legitimacy, they were in open competition with the orthodox practitioners in their search for lucrative practices. As such, they posed a direct threat to their livelihoods which had to be opposed.

By the mid-1840s a wide variety of electrical equipment, specifically tailored for medical use, had appeared. The induction coil apparatus designed by Golding Bird was being produced and sold by William Neeves, a scientific instrument maker

\footnotetext{
${ }^{69}$ For an account of the development of the induction coil, particularly as it related to medicine, see Willem D. Hackmann, 'The induction coil in medicine and physics, 1835-1877', in Christine Blondel, Françoise Parot, Anthony Turner, and Mari Williams (eds), Studies in the history of scientific instruments, London, Roger Turner, 1989, pp. 235-50. Also Margaret Rowbottom and Charles Susskind, Electricity and medicine: history of their interaction, San Francisco, San Francisco Press, 1984.

${ }^{70}$ Golding Bird, 'Observations on induced electric currents, with a description of a magnetic contactbreaker', Philosophical Mag., 3rd ser., 1838, 12: 18-22.

71 John C. Christophers, 'Anaesthesia treated by electro-magnetism', Lancet, 1846, ii: 144-5.

72 Ibid., p. 145.
} 


\section{Marketing the machine}

working in Holborn. Other instrument makers like E. M. Clarke also produced induction coils and electro-magnetic machines specifically for the medical market. ${ }^{73}$ Such instruments were small, portable, and relatively cheap. They were easy to operate without detailed knowledge of electricity. All medical practitioners could now practice electrotherapeutics.

The new technology also had the virtue of being invisible. As Christopher Lawrence has noted, technology had a rather dubious status for many nineteenthcentury medical practitioners. ${ }^{74}$ Whilst some sought to enhance their status by forging links with scientific expertise, others, particularly in London, sought to present themselves as gentlemen trained in the art, rather than the science, of medicine. Such men were unlikely to embrace electrotherapeutics, if its use was to carry with it the taint of technician. The new electrical technology overcame this difficulty by placing the actual manipulation of the machine in the hands of servants whilst the practitioners retained control over the regulation of the therapy. ${ }^{75}$

\section{ESTABLISHING A NEW CONTEXT}

This paper began with the observation that, since the latter half of the nineteenth century, a number of commentators have identified the early Victorian period as marking a decisive break in the use of electricity for therapeutic purposes. From the perspective of these commentators electrotherapeutics before the 1830s was regarded as unsystematic and empirical. Promoters of electrotherapeutics utilized new social and rhetorical resources to change the ways in which electrotherapeutics was represented.

Three main strategies were adopted by the promoters of electrotherapeutics to reconstruct their practice as viable medicine. The use of electricity in medicine had since the eighteenth century been associated with claims concerning the intimate relationship between electricity and life. The new practitioners of the 1830s and 1840s broke this link by utilizing the philosophical apparatus of contemporary force theorists, in particular Michael Faraday and William Robert Grove.

Grove's doctrine of correlation and Faraday's hierarchical analysis of force relations were used to provide a theoretical justification for the practice of electrotherapeutics without implying any ontological commitment. At the same time electrotherapeutics at Guy's Hospital was confined within a circumscribed social space where the practice could be medically regulated. ${ }^{76}$

\footnotetext{
${ }^{73}$ See for example the contents of such trade catalogues as Edward M. Clarke, Laboratory of science. List of prices of magnetical, philosophical, optical, and chemical instruments and apparatus, manufactured by Edward M. Clarke, magnetical instrument maker etc. London, c. 1840.

${ }^{74}$ Christopher Lawrence, 'Incommunicable knowledge: science, technology and the clinical art in Britain 1850-1914', J. contemp. Hist., 1985, 20: 503-20.

${ }^{75}$ Such a process can be described in terms of the redistribution and relocation of skills. Whilst previously it had been the case that skilled electricians had been necessary to manipulate an induction coil, the appearance of self-regulating coils made it possible to dispense with them since the necessary skills were internalized in the machine. This then allowed for the predominance of more strictly medical skills in the practice of electrotherapeutics. See Bruno Latour, 'Are we talking about skills or about the redistribution of skills', unpublished paper presented at 'Rediscovering Skills' conference, Bath, September 1990.

${ }^{76}$ The importance of space in defining practice is emphasized in Steven Shapin. 'The house of experiment in seventeenth-century England', Isis, 1988, 79: 373-404.
} 
Secondly, the electrophysiological researches of Matteucci were used to provide a detailed rationale for the practice of electrotherapeutics, thus avoiding the charge of empiricism. Matteucci had used electricity as an analytic tool to examine the nervous and muscular systems. In so doing he provided electrotherapeutics with a detailed account of the ways in which electricity affected the nerves and muscles under different circumstances, which could be used to present the practice as a rational form of treatment. Electrotherapeutics as a set of practices thus became linked with the practice of experimentation.

Lastly, men like Golding Bird used their links with the electrical community tc develop new electrical technologies that were easy for the medical practitioner tc apply. In this way they could overcome the claims to expertise of self-styled medical galvanists, many of whom had been trained in the use of electrical instruments through working for the new telegraph companies. New and more convenient electrical apparatus made it possible for electricity to be used by any medical practitioner.

This suggests that historians of nineteenth-century medicine and its links with science should pay close attention to both the rhetorical strategies used by different actors to justify their activities and the actual practices in which they engaged. Electrotherapeutics did not become accepted as a viable medical treatment on the basis of any detailed theoretical understanding of the relationship between electricity and the nervous system. Electrotherapeutics became accepted as a system of practices and technologies which blurred the distinction between therapy and experiment by linking itself to electrophysiology.

By the 1850s, doctors and natural philosophers were sharing a material and intellectual technology. They used the same machines and both groups justified their use by reference to the same evidential context. Links between medicine and the electrical sciences during this period were not founded on shared theoretical assumptions, but on the shared use of instruments and the shared reading of texts about the evidential significance of those instruments' behaviour. 